\title{
Positive perilymph fistula test with semicircular canal dehiscence from cholesteatoma
}

\author{
Ming-Chih Hsieh MD, Chen Chi Wu MD PhD, Shih-Hao Wang MD
}

Cite as: CMAJ 2019 January 28;191:E104. doi: 10.1503/cmaj.180799

A

54-year-old man presented to our outpatient department with left-side hearing loss and tinnitus that had progressed for several years. The patient had vertigo with nausea, which was aggravated on applying pressure over the left external ear canal and tragus. Physical examination showed left-side tympanic membrane retraction with a whitish mass at the epitympanum, suggestive of cholesteatoma. Gently compressing the left-ear tragus induced apparently left-beating horizontal nystagmus (see video, Appendix 1, available at www.cmaj.ca/lookup/suppl/ doi:10.1503/cmaj.180799/-/DC1), consistent with a positive perilymph fistula test. Pure tone audiometry showed mixed-type hearing loss of $104 \mathrm{~dB}$ in the patient's left ear and sensorineural hearing loss of $62 \mathrm{~dB}$ in his right. High-resolution computed tomography (CT) scan of the patient's temporal bone showed a soft-tissue mass in his left middle ear and mastoid cavity with left lateral semicircular canal erosion (Appendix 2, available at www.cmaj.ca/lookup/suppl/ doi:10.1503/cmaj.180799/-/DC1). These findings were compatible with cholesteatoma with lateral semicircular canal dehiscence.

During surgery, we noted that the osseous and membranous portions of the lateral semicircular canal had been eroded by the cholesteatoma (Figure 1). We removed the cholesteatoma completely and repaired the dehiscence with bone pate and temporalis fascia.

The postoperative course was uneventful and the patient's vertigo subsided. We did not detect spontaneous nystagmus and the perilymphatic fistula test was negative postoperatively. We observed no disease recurrence after 6 months of follow-up. However, audiometry showed $108 \mathrm{~dB}$ sensorineural hearing loss in his left ear (Appendix 3, available at www.cmaj.ca/lookup/suppl/doi:10.1503/ cmaj.180799/-/DC1).

Spontaneous semicircular canal dehiscence affects mainly the superior semicircular canal, whereas lateral semicircular canal dehiscence is most frequently associated with chronic otitis media or cholesteatoma. ${ }^{1}$ Dehiscence creates an abnormal connection between the inner and middle ear, leading to perilymph leakage from the cochlea into the middle ear. The prevalence of positive perilymph fistula test in patients with labyrinthine dehiscence is $<20 \%$, complicating preoperative diagnosis. ${ }^{2}$ High-resolution CT scan of the temporal bone is the best diagnostic tool, with

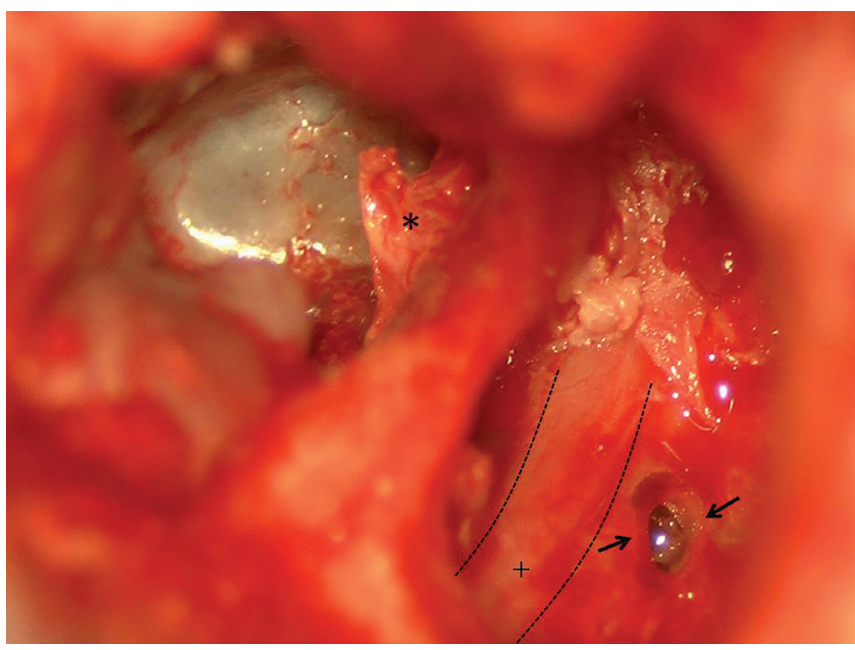

Figure 1: Microscopic view of left lateral semicircular canal dehiscence with erosion of bony and membranous sections (arrows) in a 54-year-old man with cholesteatoma. Note: *the malleus handle; +second genu of the facial nerve; dotted lines define the tympanic segment of the facial nerve.

exploratory tympanotomy as confirmation., ${ }^{3,4}$ Surgical repair is indicated and different surgical techniques, such as total removal with fistula repair or preservation of matrix over fistula, can be used depending on the specific findings in the ear., ${ }^{3,4}$

\section{References}

1. Elmali M, Polat AV, Kucuk $\mathrm{H}$, et al. Semicircular canal dehiscence: frequency and distribution on temporal bone CT and its relationship with the clinical outcomes. Eur J Radiol 2013;82:e606-9.

2. Kvestad E, Kvaerner KJ, Mair IW. Labyrinthine fistula detection: the predictive value of vestibular symptoms and computerized tomography. Acta Otolaryngol 2001;121:622-6.

3. Meyer A, Bouchetemblé P, Costentin B, et al. Lateral semicircular canal fistula in cholesteatoma: diagnosis and management. Eur Arch Otorhinolaryngol 2016;273:2055-63.

4. Parisier SC, Edelstein DR, Han JC, et al. Management of labyrinthine fistulas caused by cholesteatoma. Otolaryngol Head Neck Surg 1991;104:110-5.

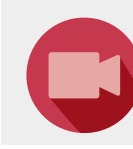

A video showing positive perilymph fistula test is available in Appendix 1, at www.cmaj.ca/lookup/suppl/ doi:10.1503/cmaj.180799/-/DC1
Competing interests: None declared.

This article has been peer reviewed.

The authors have obtained patient consent.
Affiliations: Department of Radiology (Hsieh) and Otolaryngology (Wang), Ditmanson Medical Foundation Chia-yi Christian Hospital, Chia-yi City, Taiwan; Department of Otolaryngology
(Wu), National Taiwan University Hospital, Taipei, Taiwan

Correspondence to: Shih-Hao Wang, 07164@cycy.org.tw 